\title{
Mobilidade Geográfica e Carreira: jovens universitários que querem se inserir no mercado de trabalho canadense.
}

\section{Geographical Mobility and Career: university young people who want to join the Canadian labor market.}

\author{
Tamára Cecilia Karawejczyk Telles ${ }^{1}$ \\ Mônica Carmo ${ }^{2}$
}

Submetido em 24 de setembro e aprovado em 13 de dezembro de 2019.

\begin{abstract}
Resumo: O fenômeno da mundialização proporciona mobilidade geográfica e novas oportunidades para jovens que buscam experiências de carreira intercultural. A internacionalização das organizações promove uma demanda ampliada no mercado de trabalho por profissionais competentes e qualificados em todos os sentidos. Este estudo articula os temas mobilidade geográfica, carreira e mercado de trabalho canadense, através de entrevistas com estudantes estrangeiros da Concordia University of Edmonton, na Província de Alberta/Canadá, realizadas no ano de 2018. As categorias de análise abordaram duas categorias: (a) intenções, anseios e dificuldades; e, (b) motivos para inserção profissional em pais estrangeiro, no caso o Canadá. Os principais achados da pesquisa indicam que o estudante estrangeiro está mais habituado a lidar e a enfrentar culturas e situações diferentes das suas de uma maneira mais fácil que o brasileiro. O que se pode observar é que todos anseiam crescimento educacional e profissional, ampliar networking, adquirir maior fluência no outro idioma e dar início à sua carreira, mesmo que comecem exercendo funções diferentes da sua área de estudo.
\end{abstract}

Palavras-Chave: Carreira. Mobilidade geográfica. Adaptação intercultural.

\begin{abstract}
The phenomenon of globalization provides geographical mobility and new opportunities for young people seeking intercultural career experiences. The internationalization of organizations promotes an increased demand in the labor market for competent and qualified professionals in every way. This study articulates Canadian geographic mobility, career, and labor market through interviews with foreign students at Concordia University of Edmonton in the province of Alberta / Canada in 2018. The analysis categories addressed two categories: (a) intentions, yearnings and difficulties; and (b) reasons for professional insertion in a foreign country, in this case Canada. The main findings of the research indicate that foreign students are more accustomed to dealing with and facing different cultures and situations from their own in an easier way than the Brazilian. What can be observed is that everyone longs for educational and professional growth, broadening networking, acquiring greater fluency in another language and starting their career, even if they start performing functions different from their field of study.
\end{abstract}

Keywords: Career. Geographic mobility. Intercultural adaptation. 


\section{Notas introdutórias}

Este artigo foi elaborado a partir de discussões em sala de aula relacionadas a dois projetos de pesquisa: (a) a construção de sentidos em processos de mudança: o desenvolvimento de aprendizagens coletivas e individuais em sujeitos que atuam em cargo de gestão (2011-2013) e, (b) a aprendizagem de competências gerenciais complexas para a formação gerencial: um estudo Luso-Brasileiro com empreendedores da Indústria Criativa (2015-2017), financiadas por uma Instituição de Ensino do Sul do Brasil e pelo CNPQ (edital universal). Compreender questões referentes à mobilidade geográfica, desenvolvimento de competências e mercado de trabalho é um tema emergente nas Ciências Sociais Aplicadas. Novos desafios se constroem pela superação das próprias dificuldades apresentadas em se lidar com a complexidade do mundo (MORIN, 2001; 2001a). O avanço midiático possibilitou alcance e velocidade na troca de informações, aumentando a interação entre os indivíduos e organizações e isto proporciona e facilita a conectividade entre universidades, organizações e profissionais.

Estudos sobre expatriação e interculturalidade são recorrentes na literatura (VIANNA e SOUZA, 2009; TANURE; CYRINO e PENIDO, 2007; FONSECA; MEDEIROS e CLETO, 2000; FREITAS, 2000; GALLON; SCHEFFER e BITENCOURT, 2014; CRAIDE e SILVA, 2012), porém a analise da mobilidade geográfica de jovens estudantes, é um tema recente e merecem estudos aprofundados sobre sua importância, os impactos para a vida familiar e de carreira (NETO; TANURE e ANDRADE, 2010; KARAWEJCZYK, 2016).

A internacionalização das organizações promove uma demanda ampliada no mercado de trabalho por profissionais competentes e qualificados em todos os sentidos. Para Henderson (2011) este fenômeno auxilia na criação de práticas de transferência de profissionais dentro da mesma organização em operações existentes em países diferentes da matriz, conceitualmente chamado de expatriação. Mas colabora também com a prática de aproveitamento de mão de obra especializada de estudantes que optam por estudar fora do seu pais de origem. Sejam estudantes/profissionais brasileiros ou estrangeiros, esta internacionalização acarreta a necessidade de desenvolver novas competências entre os profissionais, seja na formação de equipes multiculturais e/ou na promoção e condução 
de projetos internacionais. O Brasil, inserido neste cenário, procura ampliar introdução de profissionais e executivos brasileiros no mercado de trabalho internacional, para tornarem-se multiplicadores interculturais (ADISSI, 2009).

A formação de um profissional com experiência internacional também diz respeito a compreender questões sobre formação e capacitação. Maturana e Rezepka (2008) distinguem essas duas classes de fenômenos, esclarecendo que formação tem a ver com o desenvolvimento da pessoa e é um fundamento do processo educativo, a capacitação já seria a aquisição de habilidades e conhecimentos para a pessoa agir no mundo. Para os profissionais que querem se habilitar ao mercado de trabalho internacional, além da capacitação em conhecimentos, habilidades e atitudes do negócio da empresa, também é importante terem uma formação que conecte com a cultura e a identidade do pais em que estão inseridos. Neste sentido, o avanço dos modelos de organização do trabalho (POCHMANN, 2004) exigem não somente capacitação para o mercado de trabalho, mas também uma formação educativa.

Desta forma, os vínculos entre formação, empregabilidade e mobilidade geográfica vão se formando e a noção de qualificação remete a um julgamento legitimado, que reconhece uma pessoa capaz de exercer uma profissão ou assumir um papel profissional (LE BOTERF, 2003), no seu pais de origem ou não, apresentando uma relação dialética e um conteúdo social a formação do profissional, apontando um rompimento com uma visão pragmática de adequação da qualificação ao trabalho e incorporando dimensões sociais, éticas, culturais e políticas na formação de jovens estudantes universitários.

Este artigo tem por objetivo identificar e discutir as percepções de seis jovens universitários estrangeiros e sua experiência com mobilidade geográfica e estudantil para o Canadá, procurando compreender seus anseios, intenções e dificuldades de inserção no mercado de trabalho canadense, além de explorar os motivos pessoais para esta inserção. Esta introdução é seguida de uma seção relacionada ao referencial teórico deste artigo, onde são sumarizadas as contribuições sobre carreira e mobilidade geográfica. Logo a seguir, são apresentados os procedimentos metodológicos empregados para a coleta e análise dos dados, seguidos dos resultados obtidos e as discussões apontadas. 


\section{Carreira Profissional e Mobilidade Geografica}

Os modelos de gestão de pessoas seguem os paradigmas que constituem uma sociedade e época. A chamada administração de Recursos Humanos encontrada no final dos anos 80 do século 20, na maioria das empresas, trazia na sua essência, alguns dos ideais do paradigma moderno ou burocrático, em que o ritmo da mudança, era estabelecida por estruturas temporais precisas, altamente confiáveis e universalmente aplicáveis, tratando do passado, presente e futuro como uma mesma categoria. A própria noção tempoespaço, na era moderna, foi construida sobre um paradigma estático (BERGER, 1973; GIDDENS, 1991). Neste contexto, o conceito de carreira profissional referenciava-se apenas a qualificação formal da força de trabalho, garantida por um diploma acadêmico.

Esta concepção de qualificação formal era restrita ao cargo/ função de cada trabalhador e quanto mais este estudava e obtinha os graus inerentes a sua profissão, mais ele ascendia na sua carreira e ocupava posições diferentes na hierarquia da organização em que se encontrava, sem a necessidade de ter uma experiência internacional. Porém, com as mudanças impostas ao mundo do trabalho, no contexto da pós modernidade, este tipo conceito não consegue dar conta das novas exigências de um novo tipo de organização do trabalho, mais enxuto e flexível.

Desta forma, o conceito de carreira profissional também foi se adaptando. Antigamente, a carreira era vista como uma série de experiências e aprendizados pessoais, relacionados ao trabalho (DUTRA, 1996) em uma empresa e um pais. Adaptação pessoal e profissional em processos interculturais é um tema novo e emergente nas carreiras profissionais, onde a observação de crenças, valores, habitos, costumes e formas de viver necessitam de um ajustamento do individuo, surgindo termos como mobilidade de carreira, carreira sem fronteiras e carreira proteana (OLTRAMARI, 2008). Assim, desenvolver uma carreira no exterior, segundo Gallon e Scheffer $(2015$, p.4) é onde:

a carreira deve ser gerida e reinventada pelo indivíduo, constituindo-se em uma trajetória de vida, indo além de fronteiras rígidas, passando a valorizar as experiências internacionais. Essas começaram a serem atrativas por trazer possibilidades de desenvolvimento ou mesmo por poder impulsionamento. 
Para o ajustamento do individuo percebe ser eficaz a possibilidade de ter experiências internacionais que podem trazer chances de crescimento na carreira e maior aumento de sua empregabilidade. Lindgren e Wahlin (2001) também destacam que as organizações em termos de globalização tendem a estimular a capacidade de autoconhecimento e a exposição a contextos culturais diferentes levam o profissional a uma readequação de comportamento e até atitudes, revelando talentos e competências até então escondidos. Ressalta-se que nem todos os profissionais que almejam crescimento profissional tem como intenção à carreira internacional. Este desejo vai de acordo com as expectativas de cada indivíduo e com o contexto no qual está inserido. Porém, o profissional que opta por incluir este tipo de experiência no seu curriculo, está em busca de mudança e melhoria profissional.

Normalmente nas empresas ocorre a discordância de opiniões entre os colaboradores mesmo estando sob a mesma homogeneidade cultural. No entanto, indivíduos de diferentes países, possuem diferentes culturas, e com isso, agem de modos distintos quando se propõem a contribuir com ideias e sugestões. Essas divergências de pensamentos podem gerar conflitos e desacordos entre o grupo, tornando complexo o desenvolvimento do trabalho. Contudo, a diversidade cultural encontrada na equipe, se trabalhada de maneira correta, pode trazer resultados que não eram imaginados.

A cultura é viva, dinâmica e assim como influenciará aquele que vem, influencia aquele que recebe. A presença do estrangeiro está aí sempre e invariavelmente para nos dizer quem somos e quem não somos. (...) criar uma cultura organizacional intercultural é o mais importante e o mais difícil aspecto da globalização. (...) criar um novo modelo empresarial - seja o modelo que for e proveniente do país que for - envolve uma nova mentalidade, novos valores, novos rituais, novas práticas, novos líderes ou novos heróis que devem ser refeitos e reconstruídos nesse novo ambiente a ser criado, ou, ainda, como uma terceira cultura a ser desenvolvida. (SEBBEN, 2011, p.29).

A decisão de construir uma carreira profissional internacional entre estudantes requer planejamento a longo prazo, levando em conta o fator psicológico no que concerne a mudança de pais: apoio familiar, importância financeira ou reconhecimento profissional ou pessoal. A instabilidade financeira e política que o Brasil vem passando na última década do século XXI, favoreceu o crescimento e a intenção de optar pela mobilidade geográfica. 
A insatisfação com o cenário atual e o aumento da taxa de desemprego tem correlação com a vontade de mudança de país, onde o profissional vislumbra a possibilidade de prosperar em uma localidade com maior desenvolvimento e oportunidades Países como o Canadá incentivam a migração de estrangeiros em seu mercado de trabalho, encorajando profissionais a tentarem uma colocação nas organizações.

A mobilidade geográfica e carreira relaciona-se também com a adaptação intercultural. Não há como tratar sobre a mobilidade sem abordar a questão da adaptabilidade. Aquele profissional que não tiver ciência e sem estar preparado para lidar com situações adversas às quais está habituado, é forte candidato a falhar em sua tentativa de se inserir em outro mercado de trabalho. Calderón, Guedes e Carvalho (2016) apontam que há quatro tipos de adaptabilidade: individual, geral-fora do trabalho, interativaprofissional e organizacional cultural.

$\mathrm{Na}$ adaptabilidade individual, os aspectos a serem levados em conta são a autossuficiência, a tolerância ao estresse cultural, a desenvoltura para lidar com indivíduos com diferente bagagem cultural e a capacidade de percepção de outro; na adaptabilidade geral-fora do trabalho, procura-se compreender a cultura de toda a sociedade, ou seja, seus valores básicos, tais como: religiosidade, normas, comportamento masculino e feminino, relação com a família e crenças. Já na adaptabilidade interativa-profissional, refere-se ao entendimento, das atribuições, das necessidades e deveres do profissional no novo contexto de trabalho. Compreender que as normas e condutas existentes em empresas localizadas no país de origem não serão as mesmas encontradas no país de destino; por último, a adaptabilidade organizacional cultural que se refere a cultura organizacional da empresa que difere, mesmo que seja a mesma organização em países diferentes. Também, o suporte que o empregador irá conceder ao colaborador, tais como: acompanhamento para fase inicial de adaptação, apoio logístico como moradia, serviços bancários e saúde.

Normalmente nas empresas ocorre a discordância de opiniões entre os colaboradores mesmo estando sob a mesma homogeneidade cultural. No entanto, indivíduos de diferentes países, possuem diferentes culturas, e com isso, agem de modos distintos quando se propõem a contribuir com ideias e sugestões. Essas divergências de pensamentos podem gerar conflitos e desacordos entre o grupo, tornado complexo 
o desenvolvimento do trabalho. Contudo, a diversidade cultural encontrada na equipe, se trabalhada de maneira correta, pode trazer resultados que não eram imaginados (SEBBEN, 2011).

É importante que as corporações saibam como tratar as diversidades culturais e se usem dela para aprimorar e alcançar um bom desempenho de suas atividades. Empresas multinacionais estão mais abertas e familiarizadas com as diferenças que cada colaborador possui e buscam se utilizar disso trazer benefícios à corporação.

\section{Percurso Metodológico}

A estratégia orientadora deste estudo foi a abordagem qualitativa e exploratória, que para Flick (2013), o pesquisador participa, compreende e interpreta uma realidade, gerando maior proximidade com o objeto a ser estudado. Como este estudo foi gerado a partir de discussões sobre dois projetos de pesquisa e as experiências de inserção no mercado de trabalho canadense por uma das autoras, considerou-se pertinente esta estratégia.

No período de janeiro a maio de 2018, uma das autoras deste artigo esteve no Canadá, cidade de Edmonton na província de Alberta para realização de mobilidade acadêmica, na Concordia University of Edmonton, no Canadá. Esta experiência proporcionou a compreensão sobre a dificuldade de adaptação do brasileiro em relação aos estudantes de outros países. Apesar de sermos conhecidos por nossa receptividade e amabilidade, enfrentamos algumas barreiras culturais e falta de 'prática' para lidarmos com comportamentos alheios aos nossos; desde pequenos hábitos alimentares, interação entre colegas de aula e professores, barreiras ao falar outro idioma em tempo quase que integral ao distanciamento de amigos e familiares. No retorno ao Brasil e participando de grupos de discussão sobre carreira e internacionalização, houve o interesse em aprofundar o tema.

Assim, a coleta de dados para este estudo, ocorreu em novembro de 2018, onde foram entrevistados seis estudantes ${ }^{3}$, três brasileiros e três estrangeiros (paquistanês, russo e bengalês) na modalidade intercâmbio, no Canadá. As entrevistas foram realizadas on line e as questões se compuseram de tópicos relacionados a sua inserção no mercado de trabalho canadense. Cada entrevista durou em torno de 30 minutos, que foram gravadas e transcritas para posterior análise. 
Para definição do perfil dos entrevistados, foram selecionadas pessoas de ambos os sexos, de diferentes cursos de graduação e de diferentes países que foram ao Canadá para dar continuidade aos estudos e, concomitantemente, ingressar no mercado de trabalho canadense. Dentre o grupo de brasileiros, observa-se que sua ida ao Canadá para estudar foi determinada por uma bolsa de estudos oferecida por suas universidades. Oportunidade esta que foi aceita com a intenção de aprimorar o currículo com uma experiência no exterior, para que assim, ao retornar ao Brasil, encontrem mais oportunidades de emprego e com maiores salários, além de aprimorar o idioma em língua inglesa. Dentre o grupo de estrangeiros, observa-se que a intenção de se mudar do país de origem está mais voltada a sair da zona de conforto, ter novas experiências de vida, desenvolver o aprendizado individual e ser mais independente. A similaridade encontrada foi a de que também há a necessidade de aprimoramento do novo idioma e crescimento profissional.

\section{Quadro 1 - Perfil dos Entrevistados}

\begin{tabular}{ccccc} 
Entrevistado & Sexo & Idade & Pais de Origem & Função atual \\
\hline E1 & Masculino & 24 & Brasil & Faxineiro \\
\hline E2 & Feminino & 22 & Brasil & $\begin{array}{c}\text { Coordenador na área da } \\
\text { construção civil }\end{array}$ \\
\hline E3 & Masculino & 20 & Brasil & Desempregado \\
\hline E4 & Masculino & 21 & Bangladesh & $\begin{array}{c}\text { Atendente em loja de } \\
\text { conveniência }\end{array}$ \\
\hline E5 & Masculino & 22 & Paquistão & Assistente administrativo \\
\hline E6 & Feminino & 22 & Rússia & $\begin{array}{c}\text { Atendente em loja de } \\
\text { conveniência }\end{array}$ \\
\hline
\end{tabular}

Fonte: elaborado pelas autoras (2018).

Para a análise das entrevistas, considerou-se que as mesmas constituem-se textos em que "as falas, referem-se aos pensamentos, sentimentos, memórias, planos e discussões das pessoas e algumas vezes nos dizem mais do que seus autores imaginam" (BAUER e AARTS, 2002, p.189). Assim, após a transcrição, o corpus documental foi analisado no seu conteúdo e, como sugere Flick (2013), empregam-se categorias estabelecidas em uma combinação de quadro teórico e dos dados do campo. Por fim, o processo de interpretação e reinterpretação foi alicerçado em todos, os momentos descritos anteriormente e a 
interpretação implicou em um novo pensamento sobre o objeto de estudo, através de construções de possíveis significados (THOMPSON, 1995).

\section{Apresentação e Análise dos Dados}

Para a apresentação e análise dos dados, optou-se por dividir a apresentação em duas categorias, sendo elas: (a) entrado no mercado de trabalho canadense; (b) adaptação cultural ao mercado de trabalho canadense.

\section{- Entrada no mercado de trabalho canadense.}

Com relação as percepções dos estudos sobre a entrada no mercado de trabalho canadense, houve uma polaridade. Os entrevistados E1, E2 e E4 afirmam que foi tranquilo e tiveram apenas dificuldades com o idioma; por outro lado, os entrevistados E3, E5 e E6 afirmam que houveram entraves para suas inserções. Dentre as dificuldades apontadas estão o fato de serem estudantes e não conseguirem trabalhar full-time em uma organização e sobre o desenvolvimento de novas competencias pessoais e profissionais. Os trechos das entrevistas destacam estes fatores.

Foi tranquilo. No início foi bem diferente, tudo era diferente, inclusive as pessoas possuíam um jeito diferente de ser. Mas com o tempo e convívio tudo ficou tranquilo. Eu trabalhei como faxineiro na universidade, não encontrei nenhuma dificuldade no ambiente de trabalho, pelo contrário, as experiências se mostraram melhores do que no Brasil. (E1)

A inserção foi boa, os canadenses são em geral receptivos e sempre respeitosos. A língua continua sendo a maior barreira, como tenho que escrever muitos e-mails e às vezes falar com os clientes se cometo erros ortográficos é muito ruim para a credibilidade da empresa. (E2)

Apliquei para várias vagas em empregos como: atendente, ajudante de cozinha; trabalhos simples. Consegui umas 2 entrevistas, porém não consegui nada. Quando se é estudante é difícil conseguir algumas vagas, pois eles querem funcionários full-time. (E3)

Não tive dificuldades. (E4)

O mercado de trabalho canadense não foi fácil de entrar. Havia muitas posições não preenchidas, especialmente na indústria de alimentos. O mercado de petróleo encolheu em 2005, o que resultou em cortes de empregos e os candidatos à experiência começaram a se candidatar a empregos que exigem menos habilidades. Isso teve 
impacto negativo em pessoas como eu que estavam procurando pelo primeiro emprego. (E5)

Foi estressante, mas a prática faz a perfeição e me ajustei melhor. Melhorei a visão de currículo e sabendo o que colocar lá. (E6)

A globalização trouxe junto a inserção de um novo conceito de qualificação ao profissional, associada a um modelo de organização de trabalho qualificante, onde o indivíduo passa a fazer o seu cargo, através da incorporação de novas competências (HIRATA, 1994; TANGUY, 1997), renovando seus saberes em várias carreiras durante a sua vida profissional e com ampla possibilidade de inserir experiências profissionais internacionais em seu curriculo. No caso destes jovens universitários, mesmo tendo a expectativa de uma rápida inserção no mercado de trabalho, com a possibilidade global de mobilidade acadêmica e profissional, os empregos nem sempre são exatamento o que imaginavam. Mesmo com um novo conceito contemporâneo, o da competência do profissional, para manter sua empregabilidade necessita adquirir uma capacidade de transferência, de aprendizagem e de adaptação do trabalhador às situações novas e imprevistas (LE BOTERF, 1999), envolvendo além dos conhecimentos formais para o desempenho das atividades, um saber-fazer, que se refere a pratica cotidiana de uma profissão; o saber-ser, que mobiliza estratégias (esquemas interpretativos e modelos mentais) para compreensão do mundo social e; um saber-agir, que se distingue pela ação do comportamento nas várias situações de trabalho.

Os motivos para que estes jovens saissem dos seus paises de origem e fossem ao Canadá diz respeito ao desenvolvimento de novas competências a serem inseridas no seu curriculo, a prática e vivência em um pais que possui um idioma diferente do jovem estudante e a falta de condições do mercado de trabalho do pais de origem dos pesquisados. A instabilidade financeira e política do Brasil, Russia, Bangladesh e Paquistão como paises emergentes que são, favoreceu o crescimento e a intenção dos profissionais optarem pela mobilidade geográfica. A possibilidade de prosperar em uma localidade com maior desenvolvimento e oportunidades, estimulam tal prática. Países como o Canadá incentivam a migração de estrangeiros em seu mercado de trabalho, encorajando profissionais a tentarem uma colocação nas organizações. Hoje, em uma 
configuração mais contemporânea da carreira, não há mais garantias de estabilidade (CHANLAT, 1995; TOLFO, 2002; FONTENELLE, 2005) e quanto mais o profissional estiver alinhado com as tendências mundiais na sua área de atuação, mais preparado se encontrará para o mercado de trabalho.

Isto é observado nos seguintes trechos extraidos das entrevistas realizadas, quando questionados sobre os motivos da escolha do Canadá como um pais para intercâmbio.

Por três motivos: Melhoria de currículo, aprimoramento da língua inglesa como segunda língua e convívio com diferentes culturas. (E1)

Estudar: aprender a língua, conhecer um país diferente com o plus de possuir uma universidade Canadense no currículo. Trabalhar: o alto salário mínimo, com certeza. (E2)

Eu estava trabalhando por 3 anos na mesma empresa e desde minha infância meus pais me incentivaram a ir para fora do país por vários motivos. Acabei cansando de onde estava trabalhando e surgiu a oportunidade de vir para Canadá. Abracei a oportunidade pois queria um "recomeço", também para melhorar meu inglês e estudar novas áreas. (E3)

A má situação do meu país. A oportunidade de ir ao exterior e conhecer pessoas diferentes de diferentes culturas. (E4)

Para trabalhar em outro país, é preciso sair da zona de conforto. Ensina-nos muito através de diferentes experiências, como viver sozinho e trabalhar. Também ajuda um indivíduo a aprender sobre si mesmo e se tornar independente. (E5)

Eu sempre quis vir para outro país porque a situação em si não é tão boa, vir para a América do Norte sempre foi um sonho meu. (E6)

Em relação a profissionais advindos de países desenvolvidos, essa questão não se mostra presente e como decisória na sua escolha. Por conta de uma cultura diferente da nossa, que está mais propícia a intercâmbios culturais e, no caso dos países europeus, por conta de sua proximidade geográfica uns com os outros e por incentivo da União Europeia, favorece a este tipo de prática. No caso brasileiro atualmente a mobilidade geográfica não se faz tão presente entre os profissionais, seja por questões culturais, seja por questões economica financeiras dos profissionais. Tal fato traz consequências ao longo do processo de preparação e adaptação do profissional brasileiro ao se inserir no mercado profissional no exterior. 
O estrangeiro está mais habituado à mobilidade geográfica e não se educou profissionalmente para ser um profissional local e sim global, enquanto o brasileiro diz que pensa como global, mas age como local, tem receio de mudanças, seleciona as localidades e é movido muito por uma ansiedade típica do turista que irá fazer uma bela viagem. Ao se deparar com o dia a dia de uma cultura muito diferente da sua, muitas vezes tem dificuldades de adequação pela falta de preparo. (ADISSI, 2009).

Especificamente no caso brasileiro, embora a elevação da idade média dos brasileiros nos últimos 50 anos tenha sido significativa e, em contrapartida existir a tendência de baixas taxas de natalidade, pode-se afirmar que o Brasil é um país com um enorme contingente de crianças e jovens (FRIGOTTO, 2004). A juventude tem sido identificada como fase etária intermediária, de transição da adolescência para a fase adulta. É uma faixa etária geralmente dependente economicamente, e associada à educação e à formação, próxima da constituição de uma vida familiar e profissional própria (POCHMANN, 2004). Já Simões (2010) acredita que a juventude se evidencia quando o indivíduo apresenta a necessidade de independência em relação à família e começa a buscar a autossuficiência, porém existe a necessidade de uma readequação dos hábitos da cultura materna para adaptar-se mais rapidamente e com menos estranheza aos novos costumes.

Realizar tal prática é preciso para que a inserção nesse novo contexto seja completa e com êxito. O mercado de trabalho, principalmente em empresas multinacionais, exige uma flexibilização do profissional para lidar com diversas situações e costumes. É imprescindível que este indivíduo previamente se prepare para tais adversidades a fim de evitar equívocos e constrangimentos desnecessários.

\section{- Adaptação cultural ao mercado de trabalho canadense}

A inserção do profissional no mercado de trabalho no exterior por conta da mobilidade geográfica tem como um dos assuntos a serem explanados a adaptação intercultural. Não há como tratar sobre a mobilidade sem abordar a questão da adaptabilidade. Aquele profissional que não preparado para lidar com situações adversas às quais está habituado, é forte candidato a falhar em sua tentativa de se inserir em um 
mercado de trabalho internacional.

A diferença cultural foi mais sentida pelos brasileiros do que pelos estrangeiros. Questões como a comida, o clima e os hábitos diários influenciaram o desempenho de suas funções.

\begin{abstract}
Alimentação era ruim, comidas aqui são muito ruins. O tempo que o sol leva a nascer e se põe muda muito durante o ano, no inverno se põe às 5 da tarde e só aparece as 9 da manhã. As pessoas são muito boas aqui, são gentis, se preocupam com todos os seres humanos. Eles têm uma estrutura muito evoluída culturalmente falando, o que os leva as vezes a achar muito estranho o que acontece no Brasil, porque nem se passa pela cabeça deles fazer algumas práticas realizadas de forma errada e intuitiva em nosso país. (E1)

O jeito canadense de lidar com as situações são diferentes, pois eles são mais diretos ao ponto, sem muita intimidade. No começo achava que eram rudes, mas com o tempo percebi que é apenas o jeito deles. Você nunca vai conversar sobre assuntos da sua vida pessoal com os colegas, apenas sobre o trabalho e talvez sobre o clima. A pontualidade. (E2)

Uma das coisas é a língua, mas é tudo questão de desenvolvimento e aprendizado. Acredito também que seja mais difícil de conseguir alguma vaga na minha área porque eles sempre procuram algum canadense primeiro para preencher a vaga. Acredito que o que poderia me ajudar seriam outras perspectivas que posso passar para meus colegas. (E3)

Barreiras linguísticas e restrições dietéticas eram pequenas barreiras. Geralmente, para o meu desenvolvimento, não encontrei nenhum fator cultural que me impedisse de se desenvolver. A minha cultura ensina-me a aceitar as ideias de todos, independentemente da sua identidade e origem, o que facilitou a minha adaptação, porque por vezes é necessário comprometer-se um pouco para encontrar uma situação vantajosa para todos. (E5)
\end{abstract}

Os entrevistados expressam que a diferença cultural entre o país de origem e o Canadá é uma dificuldade encontrada nos primeiros momentos da mudança, pois até entenderem o sistema do país e se adaptarem ao novo, demanda tempo. Mesmo que essa cultura seja fascinante para a maioria dos migrantes, eles mencionam que toda a mudança tem suas dificuldades, portanto, pode-se concluir que mesmo sendo algo que agrada os sujeitos e até mesmo que os atrai para o país um dia já foi motivo de dificuldade. Somente dois entrevistados consideraram fáceis a adaptaçao intercultural. 
Nenhuma. Eu estava sempre de mente aberta. Minha cultura é muito diferente daqui, mas aprendi a ter a mente aberta. (E4)

Nenhuma. Mantendo uma mente aberta (E6)

$\mathrm{O}$ apego à cultura de origem aponta uma dificuldade em transcender este aspecto. Sebben (2011) destaca que a cultura é viva e auto influenciadora, tanto para o estrangeiro quanto para o cidadão local. Santos e Gransotto (2015, p. 203) dizem que “o multiculturalismo e o interculturalismo do Canadá se fundam sobre a capacidade de “acomodar" a diversidade cultural em um contexto inclusivo de direitos dos indivíduos".

No Canadá há uma cultura de acolhimento do estrangeiro. Isso se percebe ao fazer uma comparação com o Brasil: a expansão territorial canadense se equivale com a brasileira; no entanto, o índice populacional - 207,7 milhões no Brasil e 36,29 milhões no Canadá - mostra o porquê do incentivo à migração de estrangeiros no território. $\mathrm{O}$ multiculturalismo se aplica em uma sociedade canadense majoritariamente de língua inglesa, que "não necessita impor aos que chegam uma língua de comunicação, pois o inglês é dominante e, como eles [os imigrantes] querem participar ativamente e economicamente da sociedade de acolhimento, terão [obrigatoriamente] de dominar esta língua” (BERND, IMBERT, 2015, p 30).

Todos os entrevistados perceberam que há uma diferença da cultura organizacional que estavam habituados com a nova que se depararam.

Sim. Muito mais voltado a pessoas. Os gestores da equipe que eu participava sempre me colocaram na frente de tudo, se precisasse me ausentar por doença e coisas assim, preferiam e recomendavam que eu ficasse em casa para me recuperar mais rápido e assim voltar a trabalhar de forma mais motivada. (E1)

É uma empresa pequena e possui muitos empregados e subcontratados latinos, o que familiariza mais com o que iria encontrar no Brasil. (E2)

Muito diferente. Aqui as pessoas são mais legais e profissionais. De volta ao meu país, as pessoas são grosseiras e indelicadas em geral. (E4)

A empresa com quem trabalho é muito aberta a todas as culturas e respeita todos os indivíduos. Eu trabalho com outras 4 pessoas de diferentes origens, mas nunca tivemos um problema em relação a nada. (E5) 
Desde que eu só trabalhei na Nova Zelândia antes de ser bem parecido. No Canadá é mais rápido eu acho. (E6)

Tendo como objetivo geral analisar a mobilidade geográfica e carreira de 3 jovens estudantes universitários brasileiros e 3 estudantes universitários estrangeiros inseridos no mercado de trabalho canadense, mais precisamente na cidade de Edmonton na província de Alberta, e de acordo com a análise feita a partir dos dados coletados pelo método de pesquisa qualitativa exploratória, procurando responder o primeiro objetivo específico sobre as intenções, anseios e dificuldades ao ingressar no mercado de trabalho canadense, percebe-se que brasileiros e estrangeiros tem similaridades a divergências na motivação de suas escolhas e como se portaram em momentos de dificuldade ao ingressar no mercado.

Outro achado da pesquisa foi o que motivou estes profissionais a deixarem sua terra natal para tentarem um início de carreira em outro país. Para os brasileiros a maior motivação é a melhoria do currículo profissional que uma experiência no exterior pode proporcionar, tendo em vista que o Brasil tem por hábito fazer essa valorização. Já para os estrangeiros, o que mais levaram em conta foi à experiência pessoal e também a condição econômica que seus países vêm enfrentando.

As diferenças culturais que favorecem e atrapalham o desenvolvimento de suas atividades, percebe-se que os brasileiros demoraram um pouco a mais para de adaptarem, pois somos conhecidos por ser mais receptivos e abertos, e um costume mais fechado tende a nos impactar mais. Para Adissi (2009), o estrangeiro está mais habituado à mobilidade geográfica (...), enquanto o brasileiro diz que pensa como global, mas age como local, tem receio de mudanças, seleciona as localidades e é movido muito por uma ansiedade típica do turista que irá fazer uma bela viagem. Por último, o resultado sobre cultura organizacional que encontram na nova empresa, se difere ou não da qual estão habituados, todos entraram em consenso: a receptividade e boa cultura organizacional canadense fez com que se sentissem à vontade e bem recebidos nas empresas.

\section{Considerações Finais}

A busca por empregabilidade na sociedade impulsiona jovens de todas as partes do mundo a ampliarem sua bagagem profissional e buscarem novas experiências de vida 
e de trabalho. Com isto, muitos tem optado pela mobilidade geográfica, oportunizados pela globalização. Tanure (2007) descreve que as empresas necessitam de mão de obra qualificada e culturamente inseridas no mercado mundial e países considerados de primeiro mundo são otimas oportunidades para jovens universitários em busca de upgrade de competências e carreira.

Este artigo procurou avaliar as percepções de jovens no Canadá, como buscam sua inserção no mercado de trabalho, motivos que os levaram a sairem dos seus paises de origem e o processo de adaptação cultural a este pais. Desta forma, este estudo ressalta a importancia da mobilidade geográfica para a construção da carreira de jovens mileniuns. Entre os principais resultados observados destaca-se a dificuldade de adaptação e inserção em mercados de trabalho de paises de primeiro mundo por jovens de paises periféricos. Os estudantes não destacaram em nenhum momento a existência de um serviço da universidade em auxiliar estes jovens.

A análise dos dados mostrou que apesar de terem origens diferentes, mostraramse abertos à sua nova realidade. Além das diferenças na forma de comunicação e interação, que por momentos, para alguns, foi mais complexa, os entrevistados apresentam uma boa receptividade. Os pontos em comum que pudemos observar foram: focar no crescimento pessoal e profissional, aprimorar o idioma estrangeiro, estar em contato com uma nova cultura, conhecer a cultura de outros países, além de usufruir das vantagens que um país desenvolvido tem a oferecer.

\section{Referências}

ADISSI, Marcos. A importância dos RHIs em um Brasil de ambientes multiculturais. SEBBEN, A. (Org.). Expatriados.com: um desafio para os rhs interculturais. Porto Alegre: Artes e Ofícios, 2009, p.19-24.

BAUER, Martin; AARTS, Bas. A construção do corpus: um princípio para a coleta de dados qualitativos. BAUER, M.; ASKELL, G. (Org.). A pesquisa qualitativa com texto, imagem e som. Petrópolis: Vozes, 2002.

BERGER, Peter. The Homeless Mind. New York: Random House, 1973.

BERND, Zilá; IMBERT, Patrick. Encontros transculturais Brasil-Canadá. Porto Alegre: Tomo, 2015.

CALDERÓN, Patricia; GUEDES, Ana Lucia; CARVALHO, Rubia. Gestão internacional 
de recursos humanos: Adaptabilidade intercultural na expatriação de brasileiros. InternexT

- Revista Eletrônica de Negócios Internacionais da ESPM, v. 11, n.2, p. 6-20, 2016.

CHANLAT, Jean-François. Quais carreiras e para qual sociedade? Revista de Administração de Empresas. São Paulo, v.35, n.6, p.67-75, 1995.

CRAIDE, Aline; SILVA, Floriano. A mobilidade e a gestão intercultural nas organizações. Revista Pensamento Contemporâneo em Administração, v. 6, n. 1, p. 105-123, Jan./Mar., 2012.

DUTRA, Joel Souza. Administração de Carreiras. São Paulo: Atlas, 1996.

FLICK, Uwe. Introdução à metodologia de pesquisa: um guia para iniciantes. Porto Alegre: Penso, 2013.

FONSECA, Carolina, MEDEIROS, Maria Luisa; CLETO, Marcelo. A estrutura de filiais de transnacionais para receber gerentes expatriados: estudo comparativo de casos. Encontro Anual da Associação Nacional de Pós Graduação em Administração, XXIV, Florianópolis. Rio de Janeiro, 2000.

FREITAS, Maria Ester . Como vivem os executivos expatriados e suas famílias. Relatório de Pesquisa $n^{0}$ 7. São Paulo: EAESP/FGV/NPP - Núcleo de pesquisas e publicações, 2000.

FRIGOTTO, Gaudencio. Juventude, trabalho e educação no Brasil: perplexidades, desafios e perspectivas. VANNUCHI, P.(Org.) Juventude e sociedade: trabalho, educação, cultura e participação. São Paulo: Fundação Perseu Abramo, 2004.

FONTENELLE, Ingrid. Eu Proteu: a autogestão de carreira, entre fatos e mitos. Encontro Anual da Associação Nacional de Pós Graduação em Administração, XXIX, Florianópolis. Rio de Janeiro, 2005.

GALLON, Shalimar; SCHEFFER, Angela; BITENCOURT, Betina. "Eu fui, voltei e ninguém viu": um estudo sobre a expectativa de carreira após a repatriação em uma empresa brasileira. Cadernos EBAPE.BR. v. 11, n. 1, p. 128-148, 2013.

GIDDENS, Anthony. As consequências da modernidade. São Paulo: UNESP, 1991.

HIRATA, Helena. Da polarização das qualificações ao modelo de competência. FERRETI, Celso e outros. Novas tecnologias, trabalho e educação: um debate multidisciplinar. Petrópolis: Vozes, p. 124-138, 1994.

KARAWEJCZYK, Tamara Cecilia. Mobilidade geográfica e carreira: um estudo sobre profissionais que migraram para os Estados Unidos. Inquietud Empresarial. Vol. XVI (1), 117-143, 2016.

LE BOTERF, Guy. Desenvolvendo as competências dos profissionais. 3. ed. Porto Alegre: Artmed, 2003.

LE BOTERF, Guy. De La Compétence. Paris: Les Editions d'Organisation, 1999. 
LINDGREN, Martin; WAHLIN, Noan. Identity construction among boundary-crossing individuals. Scandinavian Journal of Management, vol.17, n.3, p.357-377, 2001.

MATURANA, Humberto; REZEPKA, Sima. Formação e capacitação humana. Petrópolis: Vozes, 2008.

MORIN, Edgar. Ciência com consciência. Rio de Janeiro: Bertrand Brasil, 2001.

MORIN, Edgar(a). Os sete saberes necessários à educação do Futuro. São Paulo: Cortez, Brasília, DF:UNESCO, 2001a.

NETO, Antonio; TANURE, Betania; ANDRADE, Juliana. Executivas: Carreira, maternidade, amores e preconceitos. RAE - Revista de Administração de Empresas. vol. 9, n. 1, art.3, jan/jun, 2010.

OLTRAMARI, Andrea Poleto. Carreira: Panorama de Artigos Sobre o Tema. Encontro Anual da Associação Nacional de Pós Graduação em Administração, XXXII, Florianópolis. Rio de Janeiro, 2008.

POCHMANN, Marcio. Juventude em busca de novos caminhos. VANNUCHI, P. (Org.). Juventude e sociedade: trabalho, educação, cultura e participação. São Paulo: Fundação Perseu Abramo, 2004.

SANTOS, Nadia; GRANSOTTO, Luciana. Expérience touristique dans des circuits patrimoniaux: une approche interculturelle Brésil-Canada. BERND, Z.;IMBERT, P. (Org.). Envisager les rencontres transculturelles Brésil-Canada. 1ed.Quebec: Presses de 1'Université Laval, 2015, v. 1, p. 213-234.

SEBBEN, Andrea. Expatriados.com: um novo desafio para os rhs interculturais. Porto Alegre: Artes e Ofícios, 2009.

SIMÕES, Claudia. Educação técnica e escolarização de jovens trabalhadores. MOLL, J. (Org.). Educação profissional e tecnológica no Brasil contemporâneo: desafios, tensões e possibilidades. Porto Alegre: Artmed, 2010.

TANGUY, Lucie. Competências e integração social na empresa. RODÉ, F. ; TANGUY, L. (org.) Saberes e Competências: o uso de tais noções na escola e na empresa. Campinas, Papirus, p.167-197, 1997.

TANURE, Beatriz; CYRINO, Ana; PENIDO, Elton. Estratégias de internacionalização: evidencias e reflexões sobre as empresas brasileiras. FLEURY, M.; FLEURY, A. (orgs.) Internacionalização e os países emergentes. São Paulo: Atlasp.198-215, 2007.

TEDESCHI, Losandro. Abordagens interculturais. Porto Alegre: Martins Livreiro, 2008. THOMPSON, John. Ideologia e cultura moderna: teoria social critica na era dos meios de comunicação de massa. Petrópolis: Vozes, 1995.

TOLFO, Susana. A carreira professional e seus movimentos: revendo conceitos e formas de atuação em tempos de mudança. Psicologia: Organização e Trabalho, vol. 2 n. 2, 3963,2002 . 
VIANNA, Nereida; SOUZA, Yeda. Uma analise sobre os processos de expatriação e repatriação em organizações brasileiras. Revista de Administração e Contabilidade da Unisinos, vol. 6, n.4, 340-353, 2009.

\section{Notas}

1 Professora permanente do Programa de Pós-Graduação em Memória Social e Bens Culturais do Unilasalle, Canoas, RS, Brasil. Tamara.karawejczyk@unilasalle.edu.br. Orientou teoricamente, acompanhou a coleta de dados e revisou o artigo no âmbito da linha de pesquisa da qual participa, Memória, Cultura e Identidade.

2 Graduada em Recursos Humanos Unilasalle, Canoas, RS, Brasil. mvnicarmo@gmail.com. Participou da coleta e análise de dados e da escrita do artigo.

3 Para este estudo, optou-se pelo anonimato dos entrevistados, porém para fins de registro a editoria da revista recebeu uma declaração do Unilasalle/Canoas com a garantia do consentimento livre e esclarecido dos entrevistados para esta pesquisa. 